\title{
DE CÓMO ORTEGA MALENTENDIÓ A GABRIEL MIRÓ
}

\author{
Guillermo LAÍN CORONA \\ UNED \\ glaincorona@flog.uned.es
}

\section{RESUMEN}

A Gabriel Miró se le ha leído tradicionalmente como estilista, lírico o poeta en prosa, ya fuera para alabarle por el virtuosismo de su prosa, ya para criticarle como mal novelista sin nada que decir. Cada vez más puesta en entredicho, aquí se propone que esta manera de leer a Miró parte en gran medida del feroz ataque que le hizo José Ortega y Gasset en una reseña sobre su novela cumbre: El obispo leproso (1926). Se analizará aquí esta reseña, poniendo de manifiesto los errores de interpretación en que cayó Ortega y cómo, en su ataque a Miró, llegó incluso a caer en contradicción con sus propias teorías estéticas, particularmente de $\mathrm{La}$ deshumanición del arte e ideas sobre la novela (1925).

Palabras Clave: Gabriel Miró; Ortega y Gasset; recepción literaria; estética de vanguardia

\section{ABSTRACT}

Gabriel Miró has traditionally been considered a stylist, a lyricist or a poet in prose, either as a means to praise the refinement of his prose or else to undervalue him as a lame novelist who had nothing to say. With more and more critics disagreeing with it, this article will argue that this inaccurate view relies on the violent attack Ortega y Gasset offers in his review of Miró's most important novel: El obispo leproso (1926). This review will be examined here in order to show that Ortega misunderstood Miró, highlighting that in his attack he contradicted his own aesthetics, particularly La deshumanización del arte e ideas sobre la novela (1925).

Keywords: Gabriel Miró; Ortega y Gasset; literary reception; Avant-Garde aesthetics. 
Para bien o para mal (para criticarle o para alabarle), la crítica ha destacado tradicionalmente en Gabriel Miró (Alicante 1879-Madrid 1930) al estilista, lírico o poeta en prosa, frente al novelista. En una demoledora reseña publicada en 1927, José Ortega y Gasset se posicionó entre quienes le atacaron, rechazando que la obra cumbre de Miró, El obispo leproso (1926), quedara «avecindada entre las buenas novelas». Ortega justifica su opinión de este modo:

Varias veces me he acercado a algún libro de Gabriel Miró. He sorbido unas líneas, tal vez una página, y me he quedado siempre sorprendido de lo bien que estaba. Sin embargo, no he seguido leyendo. ¿Qué clase de perfección es ésta que complace y no subyuga, que admira y no arrastra? ¿Es una perfección estática, paralítica, toda en cada trozo de sí misma, y que por esta razón no invita a completar lo que ya vemos de ella, apeteciendo lo que aún nos falta? Cada frase gravita sobre su propio aislamiento, sin dispararnos sobre la que sigue ni recoger el zumo de la precedente. Tal vez por esto, el movimiento, la trashumancia en que consiste la lectura, tiene que ponerlos el lector con su propio esfuerzo y empujarse a sí mismo, a pulso, de una página a otra.

así, concluye Ortega, con irónica alabanza: «¿No es esto egregio lirismo?» (2004-2010, IV:146, 146 y 147) ${ }^{1}$.

Las palabras de Ortega no hacían sino repetir un tópico que se venía fraguando desde primeros de 1900. En una reseña sobre La mujer de Ojeda (1901), J. Mingot tiene el honor «de ser probablemente el primero en valerse de lo que llegaría a ser un cliché de la crítica» (Macdonald, 2010:29). Y es que para Mingot: «es Gabriel Miró un poeta ante todo» (Cfr. Macdonald, 2010:29). Con ser, pues, un cliché extendido, no es descabellado suponer, sin embargo, que, con su reseña de El obispo leproso, Ortega, dado su peso en el pensamiento español, favoreciera a consolidarlo y perpetuarlo hasta nuestros días. Lo sorprendente es que fuera precisamente Ortega quien se hiciera eco y promoviera esta negativa lectura de Miró, tan poco afortunada. Y es que Ortega, siendo tan fino pensador, «no supo -o no quiso- captar el estilo mironiano» (Romera Castillo, 1983:13). Además, la estética de Miró se ajusta muy de cerca a los principios defendidos por el propio Ortega en sus escritos de arte y literatura. Por eso, no se comprende que el filósofo despreciara a Miró. De hecho, en su ataque, Ortega entra en contradicción con sus propias ideas.

Ya algunos críticos han intentado analizar este yerro de Ortega, pero es necesario aportar un nuevo análisis al respecto para apuntalar argumentos y ofrecer otros nuevos. El artículo ya citado de Romera Castillo es una breve reseña sobre la edición póstuma que hizo Edmund King de Sigüenza y el mirador azul (1982), por lo que se limita a alabar el trabajo del crítico anglosajón, haciendo ver que este texto de Miró, que no llegó a publicarse en vida, pretendía ser una «contestación, en modo alguno agresiva, a Ortega» (Romera Castillo, 1983:13). Por su parte, Carlos Ruiz Silva (1980:119 y 121) se refiere tangencialmente a la «adversa y desa-

\footnotetext{
${ }^{1}$ Publicación original: José Ortega y Gasset, «Un libro. "El obispo leproso”. Novela, por Gabriel Miró», El Sol, 9 de enero de 1927. Aquí se cita por la edición de las Obras completas (10 vols., 2004-2010), incluida en el volumen IV (2005:145-49). Por el amplio número de referencias a este y otros textos de Ortega, y para mayor claridad para el lector, en adelante todos se citarán por esta edición, señalando, entre paréntesis, $O C$, volumen, título abreviado de la obra en cada caso y número de página. Para evitar confusiones son el título de la novela de Miró El obispo leproso, para la reseña de Ortega se usará la abreviatura «Libro».
} 
fortunada crítica de Ortega y Gasset», llamándole «torpe y ojicorto». Pero no analiza el yerro orteguiano en sí, sino que ofrece una «Noticia sobre "Sigüenza y el mirador azul"».

Quien sí se ha detenido algo en la cuestión es precisamente Edmund King. Este crítico, en su edición de Sigüenza y el mirador azul, hace notar la injusta arbitrariedad de Ortega: «porque si en España hay mejor ejemplo que los libros de Oleza, y aún se puede decir, si hay otro ejemplo a secas, de la novela como el género moroso tan supervalorizado por Ortega en Ideas sobre la novela, los críticos todavía no lo han señalado» (King, 1982:101). King está siendo aquí algo drástico, ya que la obra de Benjamín Jarnés, por ejemplo, está muy cerca del tipo de novela de vanguardia promovido por Ortega. En todo caso, una afirmación así requiere de un tipo de explicación que hace King años más tarde, si bien parcialmente. En «Oleza: novela como iconostasio», King (1993:106-07) hace un análisis sumarísimo de las Ideas sobre la novela, y luego señala: «Los conocedores de la obra de Gabriel Miró dirán en seguida que en estas Ideas Ortega está describiendo Oleza» (107). Entonces, King pasa a describir las razones por las que Ortega atacó El obispo leproso, pero no explica en qué sentido(s) esta novela se ajusta a las Ideas de Ortega ni a la estética orteguiana en general tal y como se manifiesta en otros escritos. Tampoco pone de manifiesto King de qué manera(s) se contradice Ortega consigo mismo al atacar a Miró. Lo que hace King es explicar algunas (las más graves) equivocaciones de Ortega al leer El obispo leproso, muy especialmente en torno a su tan desacertada consideración de que los personajes de esta novela son meros estereotipos (108-13). Pero esto King sólo lo analiza como pretexto para ofrecer una (muy rica, por cierto) lectura de las novelas de Oleza. Así se pone de manifiesto hacia la mitad de su artículo. Para King, Oleza puede leerse de muchas maneras, como novela de tesis, psicológica o, entre otras posibilidades, de aprendizaje (Bildungsroman), y señala que, en última instancia, la obra es todos estos tipos de novela y a la vez ninguno de ellos. Para justificar esta interpretación, King le da irónicamente la razón a Ortega de que sería conveniente aceptar que Oleza no sea una buena novela, porque con su modo de narrar en efecto parecería que Miró «no tiene la intención de responder a ningún criterio de significado general; que es, en el mejor de los casos, una ensambladura de diversos elementos [...] sobre la cual flotan nubes informes de posibles significados» (119). Estando de acuerdo con Ortega en la dificultad de hallar un sentido general unitario a la novela, para King, sin embargo, ello no es un problema, sino un logro. Y en todo caso King sí encuentra un sentido general a la peculiar configuración de la obra como ensambladura: de este modo, además de por el uso de recursos que ocultan (sin negarlo) el paso del tiempo, se ofrece una novela como iconostasio, esto es, un montaje «de segmentos narrativos iconos». No iconos en un sentido pictórico, lo que negaría su carácter novelístico, sino iconostasio como «retablo o vitral - pensando en los que sirven un propósito narrativo» (121). No hay duda de que las contracríticas de King a las críticas de Ortega contra Miró son muy pertinentes. Pero, como se ve, King no persigue en su artículo desmontar sistemáticamente la desacertada reseña de Ortega, sino que (legítimamente, por otra parte) muestra algunos de los yerros orteguianos en torno a Miró como forma de generar una nueva lectura de Oleza como iconostasio.

En un artículo mucho más reciente, Antonio Vilanova aborda también la «incomprensión [...] que es patente y manifiesta en el famoso artículo de Ortega sobre El obispo leproso» (Vilanova, 2001:429). Pero se trata de un análisis a veces vago, que no estudia todos los yerros del filósofo y repite (aunque ampliando) las mismas ideas de King. Por ejemplo, Vilanova se sorprende del ataque de Ortega contra Miró, ya que, como King, considera que el ali- 
cantino pone en práctica las Ideas sobre la novela (430). Pero Vilanova, después de resumir tales ideas, no analiza de qué manera se ponen en efecto en práctica en Miró. Simplemente, yuxtapone a continuación su (brillante, por cierto) lectura de El obispo leproso (432-33), y el único análisis realmente contrastivo con las Ideas sobre la novela se centra en mostrar, frente a la opinión de Ortega, que los personajes de Miró, y en particular don Magín, no son meros estereotipos (434-40). Vilanova, pues, sólo aborda (si bien, con maestría) el yerro orteguiano en torno a los personajes de Miró (que es lo mismo, aunque ampliándolo, que había hecho King) y no se mete en yerros de otra índole.

Frente a esto, en el presente artículo pretendo analizar lo desacertado de la lectura que hizo Ortega de El obispo leproso, abordando todos los yerros que cometió y contrastando su propia estética con la de Miró. Para ello, no me limitaré a contrastar las Ideas sobre la novela y El obispo leproso, sino las estéticas de Ortega y Miró tal y como aparecen en otros escritos. De este modo, intento ofrecer una contracrítica a la reseña de Ortega más completa y sistematizada que la que han llevado a cabo otros académicos antes que yo, claro que sin dejar de apoyarme en los apuntes brillantes que ya estos hicieron en su momento.

\section{LOS DOS ARGUMENTOS DE ORTEGA EN SU RESEÑA}

\section{G. G. Brown fue uno de los primeros en cuestionar a Ortega:}

The idea, launched by Ortega's essay on El obispo leproso in 1927, that Miró is a mere formalist (whatever that might be) whose cult of beauty causes him to exclude from his work the action, ideas, and emotions which most people expect to find in prose fiction, will not bear a moment's serious examination. (Brown, 1972:49-50)

Según esto, el yerro de Ortega puede analizarse, pues, en torno a dos argumentos: el exceso de belleza formal («cult of beauty») y el consiguiente atosigamiento de las «actions, ideas, and emotions», o sea, del contenido.

\subsection{La belleza formal}

Con un lenguaje hiperbólico con el que evidentemente se mofa de lo que irónicamente alaba, dice Ortega:

No creo que haya actualmente escritor más pulcro y solícito. Cada frase está hecha a tórculo. Cada palabra, ensamblada con las vecinas, y luego, pulida la coyuntura. Y no hay línea que suba ni que baje en la página: todo el libro conserva la misma ardiente tensión, idéntico cuidado, pulso y pulimiento. Tanto, que acaso este son persistente de prima hiperestesiada colabora a la fatiga, no dejando respiro: la perfección de la prosa es en Miró impecable e implacable. Debe trabajar con una técnica parecida a la de un pintor primitivo que fabricaba su tabla pulgada a pulgada. $(O C$, IV, «Libro»: 146)

Sorprende este negativo juicio de Ortega. En La deshumanización del arte e ideas sobre la novela (1925), el filósofo reclama un arte artístico, destinado a «una clase muy particular 
de hombres», de especial sensibilidad para percibir las experiencias exclusivamente estéticas, no el trasfondo humano (OC, IV, Deshumanización: 850 y 851): disfrutar del cristal de una ventana (forma), no del paisaje exterior (contenido). Desde este punto de vista, ¿qué habría de malo en el cuidado «pulcro y solícito» de la prosa de Miró? Al fin y al cabo, la prosa sería la ventana alabada por Ortega. Y adviértase la contradicción en que incurre, al comparar negativamente a Miró con un pintor. ¿No es precisamente la pintura el arte que tiene Ortega en mente?

Podría pensarse que el problema es que la estética de Ortega es demasiado formalista, en el sentido de que, con su ejemplo de la ventana/paisaje, insiste en una separación tajante de forma y contenido. En este sentido, Macdonald considera que, a pesar de su aparente modernidad, Ortega tiene una visión muy arcaica del arte, cercana a las ideas del siglo XIX (Macdonald, 2010:30-31 y 56-57). Sin embargo, para Miró no hay separación entre forma y contenido, sino que, muy al contrario, «la palabra es la misma idea hecha carne» (Miró, 1952:118). Miró da a cada idea su expresión adecuada, de modo que el estilo no es ni accesorio ni retórico, sino necesario.

Ahora bien, esta explicación no es del todo satisfactoria, porque la estética orteguiana no es meramente formalista, y probablemente no sea acertado despreciarla como arcaica. En Ensayo de estética a manera de prólogo (1914), toma Ortega un ejemplo muy parecido al de la ventana: «La esencia del cristal consiste en servir de tránsito a otros objetos: su ser es precisamente no ser él, sino ser las otras cosas» (OC, I, Ensayo: 672). Pero, «si en lugar de mirar otras cosas al través del vidrio hago a éste término de mi misión, entonces deja de ser transparente y hallo ante mí un cuerpo opaco», tras el cual (en el cual) se percibe solamente una mancha de colores mezclados. El cristal así entendido es el objeto artístico: «un objeto que reúne la doble condición de ser transparente y de que lo que en él transparece no es otra cosa distinta sino él mismo». Esto acontece mejor en la metáfora, porque es ella «a la par un procedimiento y un resultado, una forma de actividad mental y el objeto mediante ella logrado» (673). Al decir que el ciprés es como el espectro de una llama muerta, el objeto que percibe el espectador no es ni ciprés, ni espectro, ni llama, sino un objeto nuevo: ciprés-espectro-llama. Es ese cristal tras (en) el cual se han fusionado los colores, en este caso tres objetos. En suma: «se trata de formar un nuevo objeto que llamaremos el "ciprés bello" en oposición al ciprés real. Para alcanzarlo es preciso someter a éste a dos operaciones: la primera consiste en libertarnos del ciprés como realidad visual y física, en aniquilar el ciprés real; la segunda consiste en dotarlo de esa nueva cualidad delicadísima que le presta el carácter de belleza» (674). Esta explicación muestra, pues, que la estética de Ortega no es exclusivamente formalista: la belleza (metáfora, objeto artístico) no se alcanza sólo mediante la palabra (forma) sino mediante una determinada manera de disponer la realidad (contenido), destruyéndola y creando una nueva. Se destruyen los objetos ciprés, espectro y llama y se crea el objeto ciprés bello, de modo que «es la esencia del arte creación de una nueva objetividad nacida del previo rompimiento y aniquilación de los objetos reales» (678).

La negativa opinión de Ortega ante la pulcritud de la prosa mironiana no puede basarse, pues, en cuestiones de forma exclusivamente. Pero, para entenderlo, antes es preciso explicar la postura del propio Miró y la estética de su tiempo. Según C. A. Longhurst (2006:126 y 128), fruto de la marcada aversión al exceso retórico de la Restauración, los escritores 
de comienzos del siglo XX compartieron «a distrust, or at the very least a questioning, of the power of language to communicate worthwhile truths», en lo que se basaría realmente el rechazo del estilo. Así: «Baroja's innate scepticism about all systems made him deeply suspicious of language as an expressive tool $[\ldots]$ hence his [...] sober, even laconic, form of expression». Miró, según Longhurst, tampoco cree que el lenguaje pueda atrapar la verdad del mundo objetivamente. Pero la creencia de Miró en la palabra como idea hecha carne supone una diferencia. No cree él en la incapacidad total del lenguaje para expresar. Miró cree solamente en su incapacidad de expresar el mundo objetivo, pero considera que sí puede expresarlo subjetivamente, hasta el punto de que lo real sólo lo es del todo cuando, según el propio Miró en El humo dormido (1919), recibe «la fuerza lírica de la palabra, su palabra plena y exacta» (Miró, 2006-2008, II:698)2 .

Edmund King (1982:45-51) ha estudiado lo aprendido por Miró de los ejercicios espirituales con los jesuitas, con los que practicó modos de imaginarse detalladamente escenas piadosas y relatarlas. Fruto de esto, según King, Miró se deleita en la contemplación del mundo sensible, pero, cuando se dispone a escribir, no ofrece lo que ve, sino la recreación subjetiva de lo visto, y la imagen que da, por ser suya, está estrechamente ligada al lenguaje usado por él para expresarla. Para sus descripciones de Palestina en Figuras de la Pasión del Señor (1916-1917), Miró usó los paisajes de Alicante, y no tuvo reparo en admitirlo: «Es verdad» (1966:314). El paisaje alicantino le sirve a él para formase, por medio de la contemplación, $s u$ idea de Palestina, y cuando la da al público lo hace perfectamente adecuada a esa visión suya y a su lenguaje.

Por esta correspondencia necesaria entre forma y contenido en virtud de la subjetividad del escritor, se comprende que, para Miró, sólo con la palabra, concretamente con la palabra lírica, llegue a asumir la realidad su plenitud: al ser lo expresado una realidad subjetiva, sólo el lenguaje del autor que la ha construido puede terminar de darle forma. Aquí se asienta el significado profundo de la noción de la palabra como idea hecha carne. La idea que el escritor quiere expresar no es una idea cualquiera ni objetiva, sino $s u$ idea, y esa idea no puede llegar a ser real, y mucho menos si ha de comunicarse a otras personas, si no es con una palabra adecuada y necesaria, que no es sino la que el autor mismo encuentra. En una frase significativa de Años y leguas (1928), Miró deja claro cómo ver (el mundo) sólo se logra plenamente a través de la palabra: «quizá por la palabra se me diese la plenitud de la contemplación» (OC, III, Años: 742). Pero a la vez la necesidad del lenguaje es tan fuerte que «1) pronunciar la palabra es acto de hacer presente un estado o una cosa, 2) el lenguaje es acto de posesión o experiencia» (Johnson, 1985:43). Así, por ejemplo, de Sigüenza, en el Libro de Sigüenza (1917), dice Miró que «en esos "días frutales" se ha oído decir a sí mismo pronunciar: "Seamos dichosos". Y al decirlo comenzaba a serlo» (OC, III, Libro: 593). Más adelante: «"Seamos dichosos", que viene a significar: "Poseamos"» (594). Como explica Johnson (1985:45): «su posesión es la posesión por medio de la percepción del mundo, del conocimiento y de la palabra». La relación de ver, pronunciar y poseer queda patente con esta cita: «era menester que lo sintiese suyo, de Sigüenza, como si al mirarlo fuese pronunciándolo hasta con silencio» (OC, III, Años: 751).

${ }^{2}$ Por el amplio número de referencias a este y otros textos de Miró, se usa siempre la edición de las Obras completas (3 vols., 2006-2008), señalándose en adelante, para mayor claridad para el lector, OC, volumen, título abreviado de la obra en cada caso y número de página, entre paréntesis. 
Resumiendo: la percepción de la realidad material suscita una imagen subjetiva (contenido) que puede y necesariamente debe ser representada por el lenguaje del sujeto perceptor (forma), y a través del lenguaje se siente la posesión de la realidad. Inversamente, el lenguaje (forma) es el camino de acceder a esa imagen subjetiva (contenido), comprenderla y sentirla como propia. Por ello, el lenguaje no poder ser algo accesorio, de ahí que Miró lo cuidada tanto.

La postura de Ortega es notablemente diferente. En Meditaciones del Quijote (1914), contrasta este filósofo el pensamiento germánico, que tiende a la profundidad de los conceptos, frente al mediterráneo, que se contenta con la superficialidad de las impresiones. Ortega reivindica lo primero, en beneficio de la meditación: «La meditación es el movimiento en que abandonamos las superficies, como costas de tierra firme, y nos sentimos lanzados a un elemento más tenue, donde no hay puntos materiales de apoyo» (OC, I, Meditaciones: 773). El modo de comprensión de la realidad se basa, no en el mundo contemplado, como lo era para Miró, sino en los conceptos: «El concepto es el órgano normal de la profundidad» (781). Ortega no puede dejar de lado lo que llama impresiones, pues sólo partiendo de ellas se puede llegar al pensamiento profundo. Pero la base del conocimiento no reside en esa contemplación (tan marcada, como se vio, en Miró) de la superficialidad o impresión, sino en un paso rápido a la meditación que se halla más allá de esa superficie. Es más, la verdadera percepción, para Ortega, no es la del mundo, sino la de los conceptos subyacentes: «el concepto será el verdadero instrumento u órgano de la percepción y apresamiento de las cosas» (784). Se da, como en sus ideas estéticas, la separación entre forma y contenido, pero porque el conocimiento se aprehende en la percepción de lo conceptual, no de lo formal. De hecho, la impresión le merece el mayor de los desprecios, y considera negativamente al pensador mediterráneo (heredero, dice, del latino) como un sensualista, a diferencia del admirado pensador germano (heredero del griego):

Para el griego lo que vemos está gobernado y corregido por lo que pensamos y tiene sólo valor cuando asciende a símbolo de lo ideal. Para nosotros, esta ascensión es más bien un descender: lo sensual rompe sus cadenas de esclavo de la idea y se declara independiente. El Mediterráneo es una ardiente y perpetua justificación de la sensualidad, de la apariencia, de las superficies, de las impresiones fugaces que dejan las cosas sobre nuestros nervios conmovidos. (778)

Sígase su razonamiento con una selección de citas, en las que Ortega va además acercándose a la teoría del arte:

Para un mediterráneo no es lo más importante la esencia de una cosa, sino su presencia, su actualidad: a las cosas preferimos la sensación viva de las cosas. (779)

[...] el placer de la visión, de recorrer, de palpar con la pupila la piel de las cosas, es el carácter diferencial de nuestro arte [mediterráneo]. No se le llame realismo porque no consiste en la adecuación de la res, de las cosas, sino de la apariencia de las cosas. Mejor fuera denominarlo aparentismo, ilusionismo, impresionismo.

Realistas fueron los griegos — pero realistas de las cosas recordadas. La reminiscencia, al alejar los objetos, los purifica e idealiza, quitándoles sobre todo esa nota de aspereza que aún lo más dulce y blando posee cuando obra actualmente sobre nuestros sentidos. Y el arte que se inicia en Roma — y que podía haber partido de Cartago, de Marsella o de Málaga—, el arte mediterráneo busca precisamente esa áspera fiereza de lo presente como tal. (780)

[...] dos castas de hombres: los meditadores y los sensuales. [...] Como para el sensual el órgano es la retina, el paladar, las pulpas de los dedos, etc., el meditador posee el órgano del concepto. (781) 
He aquí la clave. Miró contempla sensorialmente el mundo, lo asimila subjetivamente y lo expresa con un lenguaje adecuado y necesario a esa asimilación subjetiva. Como han señalado muchos críticos, la prosa mironiana es tremendamente sensual (Baquero Goyanes, 1956, y Nora, 1973), y no puede ser de otro modo, ya que la expresión adecuada a la idea subjetiva expresada debe incluir las impresiones del sujeto contemplador. Sin embargo, Ortega detesta un tipo de pensamiento que se quede en la contemplación detallada, deleitosa del mundo que se ve, y prefiere la meditación racional del subyacente mundo de las ideas y de los conceptos. Asimismo, desprecia un tipo de arte sensual, aparentista. No puede resultar extraño que critique a Miró. Nótese cómo ha ligado la tradición mediterránea (superficial) con Roma, Cartago, Marsella y Málaga. Poco le ha faltado para decir Alicante, tierra de Miró. Por tanto, lo que en el fondo critica Ortega de Miró no es el refinamiento formal de su lenguaje (que estéticamente tenía que admirar Ortega de acuerdo con su parábola de la ventana), sino ese sensualismo de Miró relacionado con un tipo de pensamiento presuntamente superficial. Así de claro queda en su crítica de El obispo leproso: «la obra de Miró es un libro espléndido, reverberante, recamado de luces y de imágenes, hasta el punto que casi ha de leerse con la mano en visera, aparando los ojos» (OC, IV, «Libro»: 146, cursiva mía). Pareciera que Ortega basa su crítica a Miró no en razones estéticas, sino filosóficas: en una divergente manera de aprehender el mundo.

Desde esta perspectiva filosófica se abre paso la otra crítica que le hizo Ortega a Miró: que, como resumía Brown en la cita dada más arriba, la belleza del lenguaje de Miró «exclu$\mathrm{de}[\mathrm{s}]$ from his work the action, ideas, and emotions». Ello se basaría en la creencia de Ortega, según la cual: «El predominio de los sentidos arguye de ordinario falta de potencias interiores» (OC, I, Meditaciones: 781). Quiere decirse: para el filósofo, el impresionista se contenta con los sentidos porque no tiene nada que decir, o no tiene capacidad para profundizar en los conceptos. Tal sería el caso de Miró, según se va a ver a continuación.

\subsection{El contenido}

La idea de que Miró es un pulcro escritor sin nada que decir puede entenderse de muchas maneras, especialmente en dos polos: que la belleza formal de Miró oculta una falta de ideas o que destruye la acción narrativa (no tiene una trama). En ambos casos queda la impresión de que Miró no cuenta nada.

\subsubsection{Falta de trama o acción narrativa}

La tradición realista decimonónica concedía a la acción una importancia capital en la novela, y por acción se entendía una coherente estructura de causa-efecto. En su ataque a El obispo leproso, Ortega habla precisamente de estructura: «La dignidad, el rango estético de la novela, estriba en ser un género; por tanto, en poseer una estructura dada, rigurosa e inquebrantable» $(O C, \mathrm{IV}$, «Libro»: 146). ¿Será posible que Ortega, uno de los padres de la vanguardia y de la regeneración novelística, reclame para la novela una estructura en ese sentido decimonónico? No parece plausible. Sin embargo, Ortega, al criticar en este aspecto a Miró, entra en contradicción con sus propias ideas. 
En sus Ideas sobre la novela, Ortega afirma que «La aventura no nos interesa hoy, o, a lo sumo, interesa sólo al niño interior que, en forma de residuo un poco bárbaro, todos conservamos» (OC, III, Deshumanización: 884). Y es que la trama es «sólo pretexto, y como hilo solamente que reúne las perlas en collar» (884), dada la «imposibilidad práctica de inventar hoy nuevos argumentos interesantes» (885), porque ya todos han sido explotados. Un ejemplo de la falta de interés del argumento para el lector es que «toda novela se cuenta en muy pocas palabras, y entonces no nos interesa» (885). Es «una generosa plenitud de detalles» (903) lo que hace interesante una novela, convirtiéndola, así, en un género tupido y moroso. (Se deja para más delante cómo para Ortega estos detalles tienen que ver con la suma de acciones, diálogos, etc., de los personajes.) Insistiendo de nuevo en la separación de forma y contenido, Ortega defiende que «La obra de arte vive más de su forma que de su material [...] y [a la forma] debe atender la crítica artística y literaria». Y explica: «acaece que se ha hablado mucho de lo que pasa en las novelas de Dostoyewsky, y apenas nada de su forma. Lo insólito de la acción y de los sentimientos que este formidable escritor describe ha detenido siempre la mirada del crítico» (890). Sin embargo: «No hay ejemplo mejor de lo que he llamado morosidad propia a este género. Sus libros son casi siempre de muchas páginas, $\mathrm{y}$, sin embargo, la acción presentada suele ser brevísima» (891).

Entonces, ¿por qué no le satisface Miró? Su obra es riquísima en ese abanico de detalles (ornamentos formales, digresiones, etc.) que deberían interesar más allá de la trama misma. Baquero Goyanes (1974), en este sentido, ha analizado el tempo lento de la novelística mironiana en paralelo a Marcel Proust. Claro que tal vez éste sea el problema. Para Ortega, en una fascinante pirueta intelectual, es necesario en la novela al menos un mínimo de trama, y critica por ello a Proust, por excesiva morosidad, y concluye: «el llamado interés dramático carece de valor estético en la novela, pero es una necesidad mecánica de ella» $(O C$, III, Deshumanización: 893). La razón que arguye es de índole psicológica: «El arte es un hecho que acontece en nuestra alma al ver un cuadro o leer un libro. A fin de que este hecho se produzca es menester que funcione bien nuestro mecanismo psicológico, y toda la serie de sus exigencias mecánicas [...] pero no posee valor estético o lo tendrá sólo reflejo o derivado. Pues bien, yo diría que el interés dramático es una necesidad psicológica de la novela» (894). Y esto en un sentido filosófico: «La pura contemplación no existe, no puede existir. Si exentos de todo interés concreto nos colocamos ante el universo, no lograremos ver nada. [...] Se olvida la demasiado humilde perogrullada de que para ver hay que mirar, y para mirar hay que fijarse, es decir, hay que atender» (895). Para lograr ese mirar: «Hace falta que algún interés vital, no demasiado premioso y angosto, organice nuestra contemplación, la confine, limite y articule, poniendo en ella una perspectiva de atención» (896). De ahí que el autor de novelas dé al lector «un mínimo apasionamiento» en forma de trama (897). En este sentido, la crítica de Ortega a Miró puede deberse a que vea en éste una excesiva reducción de la acción narrativa, lo que, como en Proust, impediría al lector fijarse y prestar atención. O sea, que en las obras de Miró no pasaría nada.

Dejo para más adelante si en efecto en las obras de Miró pasa o no pasan cosas, porque esto está muy en relación con la cuestión de la presunta falta de ideas, que se analizará en el punto 1.2.2. Por ahora, valga detenerse en lo que los personajes tienen que ver con la trama. La riqueza de detalles a la que Ortega se refiere como base del interés novelístico (frente a la trama) ha de lograrse a partir del estudio psicológico de personajes. Es en el disfrute de almas 
interesantes, y no en sus acciones, donde se encuentra el interés de la novela. Dicho con Ortega: la novela debe, en vez de «inventar tramas por sí mismas interesantes — cosa prácticamente imposible_-, idear personas atractivas» (OC, III, Deshumanización: 889). Ortega piensa, sin embargo, que los personajes de El obispo leproso son meros figurones sin trasfondo. De don Magín, Ortega opina que es inaceptable que hable como el narrador, esto es, con «la elocución de Juan Ramón Jiménez», ya que «cuanto se nos insinúa sobre Don Magín no nos ofrece pretexto para atribuirle semejantes iridiscencias de lenguaje». Además, reprocha que, siendo una de las figuras más importantes, está desdibujada: «la entrevemos apenas, y lo que descubrimos es un figurón compuesto de ingredientes tópicos» $(O C, \mathrm{IV}$, «Libro»: 147). Lo mismo dice de los demás personajes: que son meros tipos superficiales, y detesta, por ejemplo, el uso de muletillas, como que «un preste [don Jeromillo] dice “¡Leñe!” siempre que habla» (149).

Resulta en cierto modo contradictorio que Ortega reivindique para la novela el estudio tan pormenorizado de sus personajes, toda vez que con ello le está dando a su idea de novela un trasfondo humano que poco parece ajustarse a su propia concepción del arte. Pero olvídese esto, que puede tomarse como una interpretación sesgada y simplista de la noción de deshumanización. Nótese, eso sí, lo que Ortega dice al contrastar la épica con la novela: «Si las figuras épicas son inventadas, si son naturalezas únicas e incomparables que por sí mismas tienen valor poético, los personajes de la novela son típicos y extrapoéticos; tómanse, no del mito, que es ya un elemento o atmósfera estética y creadora, sino de la calle, del mundo físico, del contorno real vivido por el autor y por el lector» (OC, I, Meditaciones: 804). Resulta paradójico que de Miró critique el carácter de figurón de sus personajes, y que sin embargo aquí defienda el carácter tópico de los personajes novelísticos en general. Ahora bien, en su reseña de El obispo leproso, Ortega clarifica esta aparente contradicción: «Contra lo que al principio pudo parecer, no es tanto la creación de lo individual — cosa muy problemáticacomo la creación de tipos genéricos más profundos lo que constituye el verdadero talento del novelista. [...] Porque, como en la realidad, vendremos a averiguar la nueva especie (el tipo), no por definición abstracta, como en zoología, sino con ocasión de ver moverse a un personaje singular» $(O C, \mathrm{IV}$, «Libro»: 148-49). Pese a esta matización, Ortega insiste en que los tipos de Miró carecen de hasta ese rasgo de singularidad, y en ellos se amontonan meramente «atributos vulgares de determinada profesión o carácter» a los que añade «como folie alguna rareza» (149). Por ejemplo: «El obispo no es un nombre individual, a quien acontece ser obispo, sino que es el obispo en especie» (147).

Todas estas consideraciones de Ortega las refutan King y luego Vilanova con mucho acierto. Por ejemplo, don Magín «es la presencia cuya polifacética personalidad preside toda Oleza» (King, 1993:110) y uno de los personajes más logrados. Partiendo de esta idea, King sugiere un primer indicio (entre otros, de los que se hablará más adelante) de que Ortega no se leyó la obra entera. Y es que, si Ortega se hubiera leído Nuestro Padre San Daniel (1921), la primera parte de El obispo leproso (1926), no le parecería inverosímil la manera de expresarse de don Magín, ya que es uno de los rasgos con los que se va familiarizando el lector desde las primeras páginas de aquel libro³. También defiende King (1993:112-13) el uso de

3 Vilanova (2001:435), por razones similares, insiste en que «Ortega no había leído, o por lo menos no lo recordaba en el caso improbable de haberlo hecho, la primera parte de la novela que estaba comentando». 
leñe en boca de don Jeromillo, no como una muletilla superficial, sino definitoria de una conmovedora personalidad y una evolución de personaje. Y hace un breve repaso a «los demás [personajes] que Ortega condena por inadecuada caracterización [para] demostrar o que él asume posturas ciegamente arbitrarias para no ver lo que Miró está enseñando, o porque no lo ha podido ver porque no ha leído la primera mitad de la novela». Por ejemplo: «Decir que el obispo que prefiere la vida sencilla, la conversación de don Magín y el niño Pablo, el estudio, la reflexión, a la pompa, la retórica y todas las hipocresías de la buena sociedad olecense, y que se muere poco a poco de la lepra, "no es un hombre individual sino el obispo en especie" es —no hay otra palabra— absurdo» (King, 1993:113).

Puede que a Ortega se le escapara la riqueza de los personajes de Miró por el número tan grande de ellos que posee El obispo leproso, y en efecto es la ciudad, Oleza, la verdadera protagonista, a modo de personaje colectivo. Pero es que algo así debería ser del gusto de Ortega. Para el filósofo: «La esencia de lo novelesco [...] no está en lo que pasa, sino precisamente en lo que no es "pasar algo", en el puro vivir, en el ser y el estar de los personajes, sobre todo en su conjunto o ambiente» (OC, III, Deshumanización: 898). Recalca Ortega más adelante que en ese conjunto/ambiente está la táctica fundamental de la novela: «aislar al lector de su horizonte real y aprisionarlo en un pequeño horizonte hermético e imaginario que es el ámbito interior de la novela. En una palabra, tiene que apueblarlo [...] Hacer de cada lector un "provinciano" transitorio» (899), de modo que el interés del lector se vuelque en el mundo interior de la novela, y no fuera de ella. En Oleza, con la suma tan abundante de personajes (ninguno, pese a todo, desdibujado), siguiendo el criterio de Ortega, el lector queda perfectamente apueblado por el ambiente. Diríase: olezado.

\subsubsection{Falta de ideas}

Por último, ese no tener nada que decir que se le suele atribuir a Miró tiene que ver también con una presunta falta de ideas o temas. Justo es decir que Ortega no le hace este reproche a Miró explícitamente en ningún fragmento de su reseña. Pero se infiere de un modo indirecto. Porque la conclusión que se saca al terminar de leer su reseña de El obispo leproso es que lo único que hay en Miró es preciosismo (pulcritud y solicitud, parafraseando a Ortega), sin nada detrás. Con irónica magnanimidad, cierra Ortega su reseña, diciendo:

Cada página tiene aciertos parecidos, y todo el libro rebosa un magnífico lirismo descriptivo —que es probablemente la auténtica inspiración de Miró y no la de novelista—. Pero decir «lirismo descriptivo» no es decir nada, mientras no se precise un poco y desenvuelva lo que va plegado en esas dos palabras. Como no hay tiempo, ni espacio, ni paciencia, más vale concluir reconociendo que no he dicho nada sobre Miró. (OC, IV, «Libro»: 150)

o sea, para Ortega la cualidad de lírico no dice nada, y, aunque reconoce que, de precisar el marbete, algo podría decir, se excusa de decirlo por falta de tiempo.

Para rebatir esta postura, es preciso resumir varias de las ideas anteriormente expuestas. La creencia de que Miró no tendría nada que decir, según lo que se viene argumentando, partiría de la excesiva presencia de la pulcritud formal, dado que el exceso formal repercutiría en detrimento del contenido. Pero la forma no debería ser un problema para Ortega, porque 
cumple con su aspiración de ofrecer morosamente detalles interesantes (en este caso, belleza de lenguaje) más allá de la trama, y porque es el cristal de la ventana (frente al paisaje) en que se debe fijar el artista moderno. En cualquier caso, la forma en Miró se ajusta a su propia estética: porque es necesaria para el contenido (idea hecha carne). Finalmente (y esto es lo que ahora se va a analizar), la forma cumple en Miró funciones narrativas que trabajan en favor de contar una historia y aportar ideas y reflexiones sobre el mundo, sólo que muy sutilmente y en relación con el principio orteguiano de autopsia. Pero esto no supo verlo el filósofo.

Para Ortega, el principio de autopsia exige una novela no narrativa, esto es, que no describa los hechos, causas, consecuencias, sino que los presente, para que el lector los interprete. Y esto requiere un esfuerzo placentero por parte del lector:

Si en una novela leo: «Pedro era atrabiliario», es como si el autor me invitase a que yo realice en mi fantasía la atrabilis de Pedro, partiendo de su definición. Es decir, que me obliga a ser yo el novelista. Pienso que lo eficaz es, precisamente, lo contrario: que él me dé los hechos visibles para que yo me esfuerce, complacido, en descubrir y definir a Pedro como ser atrabiliario. (OC, III, Ideas: 884)

los hechos, así, no quedan explicitados ni explicados abiertamente, para que el lector los interprete, y la narración (el desarrollo de causa y efecto) sólo sutilmente existe bajo las acciones presentadas, que el lector debe esforzarse en poner en relación.

Esto mismo ocurre en El obispo leproso. La crítica se ha referido frecuentemente a uno de los temas más característicos de esta novela: la imposibilidad de la felicidad de unos personajes de espíritu abierto y tolerante, propicios para el amor, a causa de la fuerza represora de otros personajes que dominan la ciudad con una moral retrógrada, intransigente e incapaz de amor, apoyada en la Iglesia católica ${ }^{4}$. Miró no narra este tema, sino que presenta los conflictos de los personajes para el que el lector lo infiera, del mismo modo que Ortega pide que no se diga que Pedro es atrabiliario, sino que se presente a través de sus acciones. De todos los conflictos que presentan la imposibilidad de la felicidad en Oleza, hay uno que sobresale más (y que, por cierto, podría tomarse como ese mínimo de acción que Ortega cree preciso para captar la atención del lector): la historia de Pablo, cómo en su crecer de niño a adulto es privado de libertad y de amor, y concretamente de su amor por María Fulgencia. En última instancia, el tema de Oleza es la falta de amor, como la propia María Fulgencia grita en cierta ocasión: « ¡Si es que allí no se quiere nadie!» (OC, III, Obispo: 458). El amor, especialmente el de tipo sensual, está reprimido, y no hay nadie que exprese mejor esa (auto)represión que Elvira, la tía de Pablo. Las consecuencias de ello las presenta Miró muy a la manera orteguiana de la autopsia:

Miró no nos dice que Elvira es lesbiana, que tiene deseos incestuosos, que es paidófila. Más bien nos muestra un momento de acercamiento casi erótico a su cuñada Paulina, y el encuentro en la noche con don Álvaro, a quien por poco besa al decirle cómo ha salido vestida en ropas suyas a protegerle, y el nada reprimido beso que le estampa a Pablo en la garganta buscando su boca. (King, 1993:116).

${ }^{4}$ Véanse, por ejemplo, Ruiz-Funes (1988) y Martínez Galán (1990: 155). 
Lo mismo puede decirse respecto de las ideas (políticas, sociales, económicas...) que pueden encontrarse en El obispo leproso. No se explicita ningún ataque al clero; no se dice que la institución religiosa sea ridícula, sino que se presentan ciertos hechos y personajes que, con sus acciones, así lo ponen de manifiesto, si bien con fina ironía para que sólo el lector atento lo entienda. Por ejemplo, se presenta la descripción física de Monseñor Salom «como santo de los primitivos siglos de la Iglesia», y, después de varios atributos, se hace hincapié en su figura de mártir en tierras de infieles, desde la perspectiva de la multitud que le alaba: «Se le vio enseguida la señal de su martirio: una mano mutilada bárbaramente. Le quedaban dos dedos: el pulgar y el índice; los otros se los cercenaría el hacha, el cepo, el brasero, las púas, los cordeles, el refinado ingenio de los suplicios en que tanto se complacen los pueblos idólatras» $(O C$, III, Obispo: 379). Más adelante, Monseñor Salom explica a unos pocos que «no había sido mártir de los infieles, sino de sí mismo, y lo sería hasta su muerte». Y es que tiene la mano vendada para aprisionar en ella una figura de la Virgen como muestra de devoción. Sin decirlo explícitamente, el narrador muestra lo ridículo de esa forma de devoción, al descubrirse como algo mucho menos dramático lo que en principio se tenía por algo épico. Además, se hace mofa de la religiosidad de las masas populares, por la volatilidad de su opinión al conocer la verdadera naturaleza del muñón de Monseñor Salom, así como por un narcisismo impropio del sentimiento religioso: «Se conmovió la multitud. Algunas mujeres exquisitas llegaron a creer suya la penitencia del santo, y se amaron más a sí mismas» (380).

La autopsia también tiene que ver con la aspiración orteguiana de autonomía del arte. Ortega niega al arte toda finalidad, mucho menos política: «Para el hombre de la generación novísima, el arte es una cosa sin trascendencia» (OC, III, Deshumanización: 874). Pese a ello, una aplicación depurada de autopsia permite incorporar temas trascendentes sin atentar contra la autonomía del arte. Miró es un ejemplo de ello: la crítica a la religiosidad conservadora pasa desapercibida al no ser narrada sino presentada, porque el contenido ideológico sólo se hace manifiesto cuando el lector interpreta las acciones de los personajes. Si no se esfuerza en ello, sólo queda el arte.

Desde el punto de vista de la autonomía del arte, cabe además defender la pulcritud formal que criticaba Ortega en Miró. Porque el bello lenguaje, así como toda una serie de tópicos líricos que pueden encontrarse en la obra mironiana (exaltación de sentimientos o bucólicas descripciones de paisajes), contribuyen, por su propia naturaleza estética, a que la narración (estructura causa-efecto) y la crítica ideológico-política pasen desapercibidos. En vez de narrar, Miró presenta (autopsia), y su presentación está bellamente retocada por el lenguaje, con lo que la atención del lector se desvía de la trama (que Ortega rechaza en la novela moderna) y del contenido ideológico (a favor de la autonomía del arte, que defiende Ortega). Nada de esto supo/quiso verlo Ortega, aun respondiendo, como se ve, a su propia concepción del arte y de la novela.

\section{LAS OMISIONES DE ORTEGA EN TORNO A MIRÓ}

Hasta aquí, se han analizado los desaciertos de Ortega en su interpretación de El obispo leproso y la estética mironiana, así como las contradicciones en que incurre con su propia concepción del arte y la literatura. Ahora cabe abordar aspectos propios de la narrativa de 
Miró que ni siquiera llegó a mencionar Ortega en su reseña y que también están muy cerca de sus ideas estéticas.

\subsection{Importancia de la metáfora}

Para Ortega era éste un recurso predilecto del arte moderno. Le dedica, como se ha visto, un análisis detallado en su Ensayo de estética a manera de prólogo. En La deshumanización del arte, enfatiza: «La metáfora es probablemente la potencia más fértil que el hombre posee». (OC, III, Deshumanización: 865). Justifica incluso el uso de la metáfora en filosofía y ciencia: Las dos grandes metáforas (OC, II: 505-17). Pues bien, Miró hace un uso ubérrimo de este tropo ${ }^{5}$, con lo que es asombroso que Ortega no le dedique, no ya una alabanza, ni siquiera una palabra a la metáfora en su reseña de El obispo leproso.

\subsection{Narrativa insinuante y uso de la elipsis}

Según Miró (1932:X-XI): «en "El obispo leproso" se afirma más mi concepto de novela: decir las cosas por insinuación. No es menester —estéticamente- agotar los episodios». Ya no es sólo, pues, que Miró, como proponía Ortega, se limite a presentar, y no a narrar (autopsia), sino que, más radicalmente, no lo presenta todo: se regodea en no decir, en no presentar algunas cosas. Para ello, como ha explicado Ivette Miller (1975:14), es crucial el uso de la elipsis, que está «patente en el tratamiento del punto de vista, así como en los aspectos sintácticos y metafóricos del lenguaje: en la presentación no lineal de la cronología de sucesos, en el aparente truncamiento de la acción, en el tono irónico general de las novelas y en la técnica de la caracterización». Según Miller: «El grado de intensidad de la ilusión de la realidad sería, pues, la medida de efectividad de la novela como tal» (39). Entiéndase por ilusión de la realidad la capacidad, tomando la terminología de Ortega, de apueblar al lector en la novela, de hacerle creer en el mundo leído como el único mundo posible, sólidamente coherente, olvidando el real. Por ejemplo, Miró elide la «información en lo narrativo acerca de quién habla» (42), lo que refuerza la ilusión de realidad porque «se oyen voces, pero como en la vida, los dialogantes no se anuncian. De esta manera el narrador se elimina en parte de la escena» (43). También contribuye a este efecto la elipsis de la estructura de causa-efecto, pues así ocurre en la vida cotidiana: no siempre tenemos la explicación de todo lo que queremos comprender o las causas de aquello que presenciamos.

De esto no dice palabra Ortega en su reseña de Miró, y, sin embargo, es algo que sí tiene en cuenta para la estética de otros autores. Al hablar de Dostoyewsky, Ortega explica que su «realismo» «no está en las cosas y hechos por él referidos, sino en el modo de tratar con ellos», destacando el uso de «anticipaciones definidoras de cómo son» los personajes, y varias estrategias que fomentan el equívoco, de modo que: «El lector se ve forzado a reconstruir entre vacilaciones y correcciones, temeroso siempre de haber errado, el perfil definitivo de estas mudables criaturas» (OC, III, Deshumanización: 892). En última instancia, lo que

\footnotetext{
${ }^{5}$ Véanse, por ejemplo, Chabás (1924) y Anderson Imbert (1960:241-42).
} 
hace realista a Dostoyewsky es una especial manera de presentar en la obra los hechos, una manera que, diríase, imita a la vida misma en su naturaleza desordenada, pues aquí el ser humano nunca tiene una presentación clara y sistemática de los mismos, sino que ha de organizarlos, descifrando sus aparentes contradicciones, para llegar a una explicación coherente de lo aprehendido.

Es conveniente señalar también que:

Miró crea los personajes centrales de su biseccionado microcosmos con una técnica elíptica y saltante, donde los diferentes aspectos del personaje se proyectan en momentos también diferentes [...]. La caracterización de las figuras secundarias es aún más elíptica, ya que únicamente se reflejan las características sobresalientes convirtiendo a los personajes en imágenes caricaturescas; la caricatura aumenta proporcionalmente al papel decreciente del personaje en la novela. (Miller, 1975:107)

Esta apreciación es sin duda mucho más acertada que la de Ortega, cuando reducía a poco más que guiñoles a los personajes de Miró. En cualquier caso, lo que aquí interesa es esa reducción al mínimo (elipsis) que hace Miró de los rasgos con que se definen personalidades complejas. Recuérdese la capacidad para perfilar la sexualidad lésbica, pedófila e incestuosa de Elvira en sólo tres acciones. Pero tal vez fuera este el problema para Ortega: porque éste, como se vio, reclama la morosidad en la presentación de detalles. El filósofo quiere ver a los personajes dialogar una y otra vez, cometer errores, varios modos de generosidad o ruindad. Sin embargo, Miró, maestro de la elipsis, se contenta con darnos (cuando las da) una o muy pocas acciones representativas de los rasgos que definen a sus personajes. Los demás se eliden, sólo están implícitos. Así nos ocurre en el día a día de nuestras vidas: nunca se tienen todos los datos de las personas que conocemos. He aquí las contradicciones de Ortega: no le gusta la elipsis, porque quiere morosidad, pero la elipsis contribuye a un modo de realismo moderno que aplaude en Dostoyewsky y que critica en Miró. Podría pensarse que el problema fuera que a Ortega, para alcanzar este nueva forma de realismo más real, simplemente no le gustara el recurso de la elipsis, por no favorecer la morosidad, y sí los empleados por Dostoyewsky. Pero, en cualquier caso, Miró sí logra la morosidad por otros medios, como digresiones y descripciones líricas.

\subsection{Sucesos nimios}

Miró tiende a primar la presentación de detalles aparentemente sin importancia, deleitándose en su descripción, y esto contribuye a la aparente falta de trama:

La acción en las novelas de Miró es casi estática. Apenas ocurre algo, ya que los sucesos principales son a menudo omitidos y emplazados fuera de la escena, muy similarmente a las violentas escenas de las tragedias griegas. Su entramado reside en los detalles que preceden y siguen al suceso principal [...]. La técnica del autor quita énfasis deliberadamente a los incidentes importantes y acentúa los sin importancia que, sin embargo, dependen de los principales. (Miller, 1975:95)

No comenta nada de esto Ortega en su reseña de El obispo leproso. De haberlo hecho, tal vez no habría llegado a la conclusión de la falta de trama en Miró, sino de su moderna presentación, que supone elipsis de las acciones principales y morosidad de los detalles se- 
cundarios. Sin embargo, Ortega sí que alaba este principio en referencia a otros autores. Entre los recursos de deshumanización del arte:

el más simple consiste en un simple cambio de la perspectiva habitual. Desde el punto de vista humano tienen las cosas un orden, una jerarquía determinada. Nos parecen unas muy importantes, otras menos, otras por completo insignificantes. Para satisfacer el ansia de deshumanizar no es, pues, forzoso alterar las formas primarias de las cosas. Basta con invertir la jerarquía y hacer un arte donde aparezcan en primer plano, destacados con aire monumental, los mínimos sucesos de la vida. (OC, III, Deshumanización: 866).

Pone el ejemplo de Ramón Gómez de la Serna, por obras suyas como El Rastro (1915), donde los objetos insignificantes del mercadillo son revaluados por mediación lírica. Ortega no ve en Miró algo que alaba en de la Serna.

\subsection{Ironía}

Ortega habla del «Irónico destino» del arte nuevo (OC, III, Deshumanización: 872), y explica:

En el arte cargado de «humanidad» repercutía el carácter grave anejo a la vida. Era una cosa muy seria el arte, casi hierática. A veces pretendía no menos que salvar a la especie humana. [...] la nueva inspiración es siempre, indefectiblemente, cómica. [...] Y no es que el contenido de la obra sea cómico — esto sería recaer en un modo o categoría del estilo «humano»—, sino que, sea cual fuere el contenido, el arte mismo se hace broma. [...] Se va al arte porque se le reconoce como farsa. (873)

es una explicación que enfatiza la idea del carácter lúdico del arte, del que Ortega concluye: «Dudo mucho que a un joven de hoy le pueda interesar un verso, una pincelada, un sonido que no lleve dentro de sí un reflejo irónico» (873).

Ortega nunca llegó a apreciar la maestría con que Miró se valía de la ironía y del humor, pero ambos rasgos deberían haber sido de su gusto, particularmente por su común admiración por Cervantes. Las Meditaciones del Quijote son una prueba clara de esta admiración en el caso de Ortega. Y, de Miró, Guillén (1972:174) opina: «Cervantes le ha fortalecido aquel poder — sin duda innato- de confrontar un amistoso cotejo de zonas que a la vez se exaltan y rebajan con simpatía y crítica. Por eso persiste el valor de aquello mismo en que no se cree del todo». Es fascinante el malicioso retrato del historiador de Oleza al comienzo de Nuestro Padre San Daniel. Aquí, la sabiduría — que Miró no deja de admirar - se alaba sólo irónicamente. Y es que, gracias sobre todo a los atributos caricaturescos y cómicamente hiperbólicos, en el fondo se debe percibir como algo huero, pedante y ridículo:

He visto un óleo del señor Espuch y Loriga: en su boca mineralizada, en sus ojos adheridos como unos quevedos al afilado hueso de la nariz, en su frente ascética, en toda su faz de lacerado pergamino, se lee la difícil y abnegada virtud de las comprobaciones históricas. Todos sus rasgos nos advierten que una enmienda, una duda de su texto, equivaldría a una desgracia para la misma verdad objetiva. (OC, III, Nuestro:71) 


\subsection{Dificultad/Impopularidad}

Ortega sostiene que «el arte nuevo tiene a la masa en contra suya, y la tendrá siempre. Es impopular por esencia: más aún, es antipopular». Y ello porque la masa, la mayoría del público «no la entiende» (OC, III, Deshumanización: 848 y 849). Para entender el arte nuevo, es preciso una formación y una sensibilidad de que no dispone la mayoría, así como de un esfuerzo intelectual a que no ésta está dispuesta. La producción literaria de Miró es, en efecto, difícil, y requiere de un lector formado, con lo que no contó nunca con un público de masas. Desde este punto de vista, no tiene sentido que Ortega critique en El obispo leproso que la dinámica narrativa tiene que ponerla «el lector con su propio esfuerzo y empujarse a sí mismo, a pulso, de una página a otra» (OC, IV, «Libro»: 146).

\section{CONCLUSIÓN}

El análisis de los escritos estéticos de Ortega, en contraste con la obra de Miró, muestra que aquél erró en su lectura de éste y que incluso al atacarlo cayó en contradicciones con su propio pensamiento. Ortega no supo (o no quiso) ver los principios estéticos tan modernos que Miró puso en práctica y que, paradójicamente, el filósofo defendía en sus escritos teóricos y en otros novelistas. Se ha señalado que en Miró funcionan principios orteguianos como los de autonomía del arte, autopsia, ironía o metáfora. También se ha explicado que posiblemente la malinterpretación que hace Ortega del cuidado formal de la prosa de Miró como mero estilismo se deba a una diferente manera de concebir la aprehensión del mundo, más conceptual y menos sensorial para el filósofo, y se ha hecho notar que, en todo caso, ello responde más a razones filosóficas que estéticas.

En el fondo, el problema es que se dan ligeras discrepancias en la concepción del arte entre ambos autores. Por ejemplo, a Ortega parece no satisfacerle la técnica de la elipsis o la prosa sensualista de Miró. Este tipo de discrepancia es inevitable, pues diferencias hay entre todos los autores. Pero lo que aquí se ha hecho notar es que en lo esencial comparten muchos principios, inevitablemente también, siendo ambos hijos de una misma época. En efecto, La deshumanización del arte e ideas sobre la novela (1925) de Ortega es uno de los ensayos capitales en la delineación teórica de la estética de vanguardia, y de hecho se toma como referente de lo que la crítica anglosajona denomina Modernism: el arte y la literatura occidentales de entre finales del siglo XIX y aproximadamente $1930^{6}$. Y también la producción novelística de Miró debe entenderse como una evolución del realismo al Modernism (Laín Corona, 2012). Lo sorprendente es que, a pesar de todo lo que tienen en común, por unas leves discrepancias, Ortega minusvalorare tanto a Miró, habida cuenta de que, según el filósofo en sus Ideas sobre Pío Baroja (1916): «no es lícito censurar a un autor porque no abriga las mismas intenciones estéticas que nosotros tenemos. Antes de juzgarlo tenemos que entenderlo» (OC, II:217).

¿Por qué entonces criticó Ortega la obra de Miró? Aquí sólo cabe la especulación. Puede ser que existiera algún tipo de rencilla personal entre ambos. La idea es plausible si se

\footnotetext{
${ }^{6}$ Véase, por ejemplo, Bradbury y McFarlane (1991).
} 
considera que Miró quiso defenderse del ataque de Ortega en un ensayo que nunca llegó a terminar y del que hoy se conservan tres borradores: «Sigüenza y el mirador azul», publicado póstumamente (Miró, 1982). Pudiera ser incluso que Ortega no se hubiera leído a Miró, o no del todo, que acaso sólo se hubiera leído El obispo leproso, y no su primera parte esencial, Nuestro Padre San Daniel, con la que forma un todo. A las consideraciones ya dadas al respecto, añádase un dato material clave: Ortega no tuvo en su biblioteca un ejemplar de la edición de Nuestro Padre San Daniel de 1921, que era la única disponible cuando él escribió su reseña (King, 1993:112 y 124 n. 4). Y no se olvide que el propio Ortega reconoce no haber leído ninguna obra de Miró entera: «Varias veces me he acercado a algún libro de Gabriel Miró. He sorbido unas líneas, tal vez una página, y me he quedado siempre sorprendido de lo bien que estaba. Sin embargo, no he seguido leyendo» (OC, IV, «Libro»:145).

¿Se dejó llevar Ortega simplemente por los tópicos de la época, que coincidían en llamar a Miró meramente estilista? Esto es arriesgado de defender en un pensador de la talla de Ortega, pero a la vista de las contradicciones, ¿quién sabe? Además, de su ejemplar de $E l$ obispo, se limitó a hacer unas pocas marcas (líneas verticales en rojo) y recortó (literalmente, ¡arrancó!) unos pocos fragmentos, lo que le lleva a pensar irónicamente a King (1993:111) «que con los textos apartados que quería comentar no tenía que volver a mirar la novela». Es decir, este proceder parece indicar que Ortega estuviera sólo interesado en espigar unos pocos fragmentos de El obispo que, fuera de contexto, se ajustaran a unas ideas preconcebidas. En efecto, las ideas de Ortega en su reseña se corresponden con las que hasta entonces se habían extendido en prensa de manera tópica.

De un modo u otro, bien por asumir acríticamente clichés previos, o bien por (una poco acertada) convicción, lo que está claro es que Ortega se adhirió a la interpretación negativa de Miró como estilista, no como verdadero novelista, que ya se había estado formando desde los primeros años de 1900. De hecho, por su peso intelectual, su interpretación de Miró ha tenido que contribuir a afianzar y perpetuar el manido marbete de estilista. Así, refutar la crítica de Ortega ha de redundar, pues, en favor de una mejor comprensión de la obra de Miró, como novelista de vanguardia. No es poco. Quizá en una lectura más exhaustiva de los no pocos volúmenes de las obras completas de Ortega se halle algún día una pista que aclare la razón de su yerro.

\section{REFERENCIAS BIBLIOGRÁFICAS}

Anderson Imbert, EnRIQue: «La creación artística en Gabriel Miró», en Crítica interna, Madrid, Taurus, pp. 229-46.

Baquero Goyanes, Mariano (1956): «La prosa neomodernista de Gabriel Miró», en Prosistas españoles contemporáneos, Madrid, Rialp, pp. 173-252.

- (1974): «Tiempo y "tempo" en la novela», en G. Gullón y A. Gullón, eds., Teoría de la novela, Madrid, Taurus, pp. 231-42.

Bradbury, Malcolm, y McFarlane, James, Eds. (1991): Modernism: A Guide to European Literature (1890-1930), London, Penguin.

Brown, G. G. (1972): «Gabriel Miró», en A Literary History of Spain: The Twentieth Century, LondonNew York: Ernest Benn-Barnes \& Noble, pp. 45-53.

Chabás, Juan (1924): «Crítica concéntrica. Gabriel Miró», Alfar, 38, pp. 7-14.

Guillén, Jorge (1972): Lenguaje y poesía, Madrid, Alianza. 
Johnson, Roberta L. (1985): El ser y la palabra en Gabriel Miró, Madrid, Fundamentos.

KING, EDMund L. (1982): «Introducción biográfica, transcripciones y enmiendas», en Gabriel Miró, Sigüenza y el mirador azul y prosas de «El Íbero», ed. Edmund L. King, Madrid, Ediciones de la Torre, pp. 13-101.

- (1993): «Oleza: novela como iconostasio», en AA.VV., La novelística de Gabriel Miró. Nuevas perspectivas, Alicante, Instituto de Cultura «Juan Gil-Albert»-Diputación, pp. 103-25.

Laín Corona, Guillermo (2012): «La narrativa de Gabriel Miró: del realismo al Modernismo», en Realismos y decadentismos en la literatura hispánica, eds. Ricardo de la Fuente Ballesteros y Jesús Pérez Magallón, Valladolid, Universitas Castellae, pp. 239-61.

Longhurst, C. A. (2006): «Telling Words: Unamuno and the Language of Fiction», Bulletin of Spanish Studies, 83.1, pp. 125-47.

Macdonald, IAn. R. (2010): Gabriel Miró: Su biblioteca personal y su circunstancia literaria, trad. Guillermo Laín Corona, Alicante, Universidad de Alicante.

Martínez Galán, Rosario (1990): Arte y técnica en la narrativa de Gabriel Miró, Cádiz, Universidad de Cádiz.

Miller, Ivette E. (1975): La novelística de Gabriel Miró, Madrid, Códice.

Miró, Gabriel (1932): «Autobiografía», en Obras completas. Edición conmemorativa emprendida por los «Amigos de Gabriel Miró», ed. P[edro] C[aravia], 12 vols., Barcelona, Altés, 1932-1949, vol. I, pp. X-XI.

- (1952): «El párrafo; la palabra. "Azorín”», en Glosas de Sigüenza, Buenos Aires-México, Espasa-Calpe Argentina, pp. 117-20.

- (1966): «Lo viejo y lo santo en manos de ahora», en Vicente Ramos, ed., Literatura alicantina, Barcelona, Alfaguara, pp. 300-17.

- (1982): Gabriel Miró, Sigüenza y el mirador azul y prosas de «El Íbero», ed. Edmund L. King, Madrid, Ediciones de la Torre.

- (2006-2008): Obras completas, 3 vols., ed. Miguel Ángel Lozano Marco, Madrid, Fundación José Antonio de Castro.

Nora, Eugenio G. DE (1973): «La novela sensual de Miró», en La novela espanola contemporanea. Tomo 1, 1898-1927, Madrid, Gredos, pp. 431-66.

Ortega y Gasset, José (2004-2010): Obras completas, 10 vols., Madrid, Fundación José Ortega y Gasset-Taurus.

Romera Castillo, José (1983): «Gabriel Miró y Ortega frente a frente», Ínsula. Revista de Letras y Ciencias Humanas, 440-441, p. 13.

Ruiz-Funes, Manuel (1988): «Introducción» a Gabriel Miró, Nuestro Padre San Daniel, ed. Manuel Ruiz-Funes, Madrid, Cátedra, pp. 9-88.

Ruiz Silva, CARLos (1980): «Noticia sobre "Sigüenza y el mirador azul". Respuesta inédita de Gabriel Miró a José Ortega y Gasset a propósito de una crítica de El obispo leproso"», Castilla: Estudios de Literatura, 1 (1980), pp. 119-24.

Vilanova, Antonio (2001): «Ortega y Gasset y El obispo leproso», en Prosa y poesía: homenaje a Gonzalo Sobejano, ed. Christopher Maurer, Jean François Botrel, Yvan Lissorgues y Leonardo Romero Tobar, Madrid, Gredos, pp. 429-40. 
